Article

\title{
Assessment of Ghana's Comparative Advantage in Maize Production and the Role of Fertilizers
}

\author{
Lilli Scheiterle * and Regina Birner
}

Institute of Agricultural Sciences in the Tropics (Hans-Ruthenberg-Institute), University of Hohenheim, Wollgrasweg 43, 70599 Stuttgart, Germany; Regina.Birner@uni-hohenheim.de

* Correspondence: Lilli.Scheiterle@uni-hohenheim.de

Received: 19 August 2018; Accepted: 9 November 2018; Published: 13 November 2018

\begin{abstract}
Maize is one of the most important cereal crops produced and consumed in West Africa, but yields are far under their potential and the production gap leads to growing import bills. After the structural adjustment program, fertilizer subsidies again became a popular intervention to increase yields in most African countries. Ghana introduced fertilizer subsidies in 2008, with high government expenses. This study assesses the competitiveness of Ghanaian maize production and the significance of socio-economic and management variables in determining high yields in northern Ghana. Household survey data and secondary data were applied in a Policy Analysis Matrix (PAM) to test private and social profitability of the fertilizer subsidy policy. Additionally, a probit model is used to determine the characteristics that contribute to higher yields. The results suggest that production systems with Ghana's above-average yields of $1.5 \mathrm{Mt} /$ ha are profitable at household level and contribute to its economic growth, whereas production systems below this threshold report negative social profits and depend on government intervention. However, fertilizers did not increase the likelihood of a household to fall in the category of high-output production system, whereas the use of improved seeds and herbicides does. In conclusion, the analysis highlights the importance of additional measures, especially the use of supporting inputs as well as management practices, to increased maize productivity.
\end{abstract}

Keywords: maize; Policy Analysis Matrix; comparative advantage; probit; Ghana

\section{Introduction}

Addressing persistent yield gaps remains a challenge in West Africa. Achieving higher yields is not only important for food security, improved diets, and higher income but it is also a precondition to foster crop use diversification for development of both food and non-food bio-based products [1]. Agriculture is an important sector in Ghana, crop production accounts for about $23 \%$ of Ghana's gross domestic product (GDP) and employs one fourth of the country's households [2]. Ghana is informally divided between the south and north. The northern part of the country suffers from poorly developed infrastructure whereas the south has more natural resources, such as minerals, it calls upon a better educated labor force and has a more developed infrastructure with access to the Gulf of Guinea and the lake Volta. Compared to the bimodal rains in the south, the north suffers from unfavorable climatic conditions for crop production due to the single rainy season and high temperatures, nevertheless agriculture it is still the main source of employment (over $60 \%$ ) and maize is the main crop grown, the Northern region in particular, ranks fifth in the country average maize production (three years average, 2013-2015) [2]. In Ghana, maize is broadly appreciated as a stable crop and it is grown in all agro-ecological zones. More than $50 \%$ of rural households cultivate it, traditionally under rain fed conditions. In addition, also $16 \%$ of urban households are involved in its production [3]. However, the yield gap is severe, especially in the north. Average maize 
yields fluctuate between 1.2 and 1.9 metric tons (Mt) per hectare (ha), whereas on-station and on-farm trials suggest that yields average between 4 and $6 \mathrm{Mt} / \mathrm{ha}$ of maize are attainable in the country [4]. Agricultural production below production potential, especially for maize yields, is a common phenomenon in most African countries. Generally, it is stated that low yields correlate with low input use and poor technology adoption [5]. Over the past decade, mainly after the successful Malawian fertilizer program between 2005 and 2007, fertilizer subsidy programs have become one of the most popular agriculture policies in Africa. The vision for the program is to increase fertilizer use by smallholder farmers, to improve productivity and to contribute to food security [6]. However, there is no evidence of the efficiency of this policy. The study aims to assess the impact of a fertilizer subsidy program on the private and social profitability of maize production in the more neglected area of the country.

Ghana represents a good case study country as it has operated the fertilizer subsidy program (FSP) since 2008 to counter the high fertilizer cost of 2007. At inception, the FSP, was implemented through a voucher system, which was not crop-specific and not wealth-dependent, that enabled farmers to have access to fertilizer at $50 \%$ of the retailer's price. In 2010, the mode of delivery changed to the 'waybill system', which enabled all farmers to access the subsidized prices, but implied high costs for the government $[7,8]$.

As the yield gap and the increasing demand for maize, led to high import bills the government has invested greatly in the FSP. The average expenditure for the program is about $20 \%$ of the total expenses of the Ministry of Food and Agriculture (MoFA), reaching up to 53\% in 2012 [9]. Import bills in some years exceeded the amount spent on the fertilizer subsidies. In the best-case scenario, the FSP would address the yield gap and the country could be self-sufficient on maize production. Given the high cost of imports despite the FSP, the question arises whether the country has a comparative advantage in maize production or if it would be economically more efficient to import entirely the maize for domestic consumption.

This study empirically investigates whether Ghana has a comparative advantage in maize production under current world prices and domestic policies. To pursue this objective, we apply the Policy Analysis Matrix (PAM) to evaluate the effectiveness of government FSP on the maize production system. As a budget-based method, it measures the effects of a policy on private and social revenues, costs, and profits. Furthermore, the aim is to estimate, based on households' socio-economic characteristics and management factors, the probability that a farm is classified as one with an above-average maize yield. To do so, we applied a probit model to identify the factors that contribute to higher outputs, especially to analyze the role of fertilizers. Ultimately, the study aims to assess whether the country has a comparative advantage to produce maize in the north and how fertilizers contribute to the probability of a farmer to achieve above-average production maize

The rest of the paper is organized as follows: Section 2 provides a description of the research method. The empirical results are presented in Section 3 and in Section 4 provide the discussion of the results. Concluding remarks and summary of the papers main findings are presented in Section 5.

\section{Methodology}

The following section will provide detailed information on how the data was collected and the research methods applied to assess the efficiency of resource use and the role of single inputs in the above-average production systems.

\subsection{Data Collection}

The household data being analyzed in this research is from a comprehensive household survey conducted from May to July 2011 in three different regions in northern Ghana: Sissala East (Upper West), Tolon-Kumbungu, Yendi (Northern Region) and Nkoranza (Brong Ahafo). The questionnaire captured data on maize production of 2010. A two-stage clustered sampling procedure was followed. The sampling is based on a work by Winter-Nelson and Aggrey-Fynn (2008), which was based 
on data from 2007 before inception of the FSP [10]. This approach enabled us to compare the two studies. First, the four districts in the northern sector were selected; then, a sub-cluster was taken from a list of all communities belonging to the district, and at this stage three were randomly selected. In each sub-cluster of communities, a random selection of maize farmers was made. This system yielded 175 datasets on maize-producing households. The farmers within the districts share common characteristics, such as relatively scarce use of inputs, non-irrigated cultivation, and limited mechanization.

For analysis, we divided the dataset at the threshold of $1.5 \mathrm{Mt} / \mathrm{ha}$ as it represents the average maize production in the country and we distinguish between high and low producing systems. This allowed to investigate the differences between the systems, and to draw specific conclusions.

Prices, taxes, and levies needed to compute the social costs (both in the crop budget and in the PAM) were acquired from documents and reports from the Ministry of Trade and Industry (MoTI), Customs Exercise and Preventive Service (CEPS) the custom division of the Ghana Revenue Authority (GRA). Additional information on extension services and crop production's features and challenges were recorded during interviews with the MoFA and at Savanna Agriculture Research Institute (SARI).

For triangulation purposes, data on fertilizer, agrochemicals, and transport costs have been recorded from the local markets during informal talks.

\subsection{Conceptual Framework}

The data was used to construct the PAM and a probit model. For an increased accuracy, the effective plot sizes were measured by GPS devices. The two types of output systems (divided by above or below national average maize production) were considered separately. The framework allows assessing which of the systems is profitable at private and social prices (including family labor costs). Additionally, the probit model enables to estimate the determinants of the high maize productivity farms.

The PAM approach was developed by Monke and Person (1989) to address three principal issues: First, most important for ministries of agriculture, it represents a tool to determine how agricultural policies affect farming profits. Second, how policies impact the economic efficiency of the analyzed system and how this pattern can be, eventually, influenced by public investment. The third issue is related to the allocation of future funds, with the main concern of increasing social profits by improving crop yields and reducing social costs. Additionally, the PAM can be used to estimate the impacts of alternative policies on economic performance and income levels of the researched systems. The PAM includes several theoretical assumptions and empirical simplifications, but the results are theoretically consistent and valuable for policy makers [11].

Therefore, the PAM ultimately contributes to "identify how a given agricultural policy or investment would be likely to affect the general performance of the economy and the private income of farmers" [10] (p. 9). Because of the importance of this topic from a point of view of policy effectiveness, a probit model was applied to estimate the partial effect of the determinants of high-yield maize farmers. Determinants are suggested by the literature and observation from the field; the model included both socio-economic regressors as well as plot-specific input factors.

\subsection{Policy Analysis Matrix}

The PAM is a general equilibrium and policy-orientated simulation model, which can disaggregate crop production activities by revenues and costs (tradable and non-tradable inputs) [9]. Table 1 shows the how the matrix is constructed. It is used to measure the contribution of a specific agricultural system to a famer's private income and to the overall economy. This approach enables to compare and identify policies that contribute to increase household and national income [11]. The advantage of this approach is that it quantifies the economic efficiency of a given production system and the effects of policies on production technologies. The PAM uses farms budgets, to estimate separately the effects of micro and macro policies, market failures and distortions along the different stages in the 
production chain. Therefore, the outcome of the matrix facilitates assessing the policies that support the development of new technologies [12].

Table 1. The Policy Analysis Matrix (PAM).

\begin{tabular}{ccccc}
\hline & \multirow{2}{*}{ Revenues } & \multicolumn{2}{c}{ Cost } & \multirow{2}{*}{ Profits } \\
\cline { 3 - 4 } & & Tradable Inputs & Non-Tradable Inputs & \\
\hline Private Prices & $\mathrm{A}$ & $\mathrm{B}$ & $\mathrm{C}$ & $\mathrm{D}$ \\
Social prices & $\mathrm{E}$ & $\mathrm{F}$ & $\mathrm{G}$ & $\mathrm{H}$ \\
Divergence & $\mathrm{I}$ & $\mathrm{J}$ & $\mathrm{K}$ & $\mathrm{L}$ \\
\hline
\end{tabular}

Source: Monke and Person 1989. D = A - B - C Private Profits; H = E - F - G Social Profits; I = A - E Output Transfers; J = B - F Input Transfers; K = C - G Factor Transfers; L = D - H = I - J - K Net Transfers.

The first row represents revenues and costs of private prices and reflects what farmers face in the existing market. Costs are divided into two categories: tradable inputs (e.g., fertilizer and fuel) and domestic factors of production, which are generally considered non-tradable in nature (e.g., land, labor, and capital). The costs include the effect of policies e.g., tax, subsidies. Ultimately private profits are calculated through the difference between revenue and both tradable and non-tradable inputs. This data was collected in using the household questionnaire.

The second row represents values adjusted from the first row (private prices), using economic prices. As proxy for the economic prices, world market prices adjusted to their import and export parity prices are used. Opportunity costs are used to estimate the domestic factors of production. For this purpose, we made use of the secondary data collected from statistical departments of the ministries and research institutions in Ghana. The sign of the social profit is important to determine the production system's performance. A negative sigh indicates that social costs exceed the costs of import and the sector relies on economic intervention to function.

The third and last row is calculated by subtracting the values of the social prices from the private prices. It shows the effect of distorting policies and market failures on economic efficiency. It includes the value of the output transferred from society to individuals $(A-E)$. The same method can be applied for transfer of tradable and non-tradable inputs $(B-F)$ and $C-G)$. Economic efficiency can be measured by social profits $(\mathrm{H})$, which is calculated by subtracting the costs of tradable and non-tradable inputs $(F+G)$ from social revenues (E). Social values are calculated, in the case of exported goods in F.O.B. (free on board) prices and import goods in C.I.F. (cost, insurance, freight) prices. The private profitability indicates the competitiveness of a given commodity at its current technology, input costs, output prices and policy transfers. If the value is higher than 0 , it implies a comparative advantage.

\subsection{Additional Indicators for Policy Analysis}

The PAM additionally enables to compute indicators of distortion and comparative advantage. The Effective Protection Coefficient (EPC) is measured as a ratio between the value added in the domestic market and the value added in the international market prices $((\mathrm{A}-\mathrm{B}) /(\mathrm{E}-\mathrm{F}))$. A value greater than 1 indicates a positive commodity policy (e.g., subsidy to farmer); if the EPC value is less than 1, it means that negative incentives to farmers (e.g., taxes) are applied. Cost Benefit Ratio (CBR) is a broader measure of economic efficiency and indicates private profitability $((F+G) / E)$. $C B R<1$ implies private profit. The Domestic Resource Cost (DRC) measures the comparative advantage or the economic profitability of crop production. The case of social costs for land cannot be assessed because of lacking information on alternatives, as the DRC can be calculated with respect to labor and capital only. The DRC is the ratio of the value of non-tradable inputs to the value added in economic terms $(G /(E-F))$; furthermore, it is used as a proxy to measure social profits. It indicates the cost of the non-tradable inputs that must rise to get one more unit of value added in economic terms. The lower the value (lower than 1 ), the greater the country's comparative advantage in its commodity production. The Nominal Protection Coefficient for Outputs $\left(\mathrm{NPC}_{\mathrm{O}}\right)$ and tradable inputs $\left(\mathrm{NPC}_{\mathrm{I}}\right)$ are ratios of the 
private value to the social value, respectively for revenues and the tradable inputs. The Nominal Protection Coefficient (NPC) is used to determine how well government policies give incentives to grow specific crops. If the NPC (A/E) of a crop is greater than 1, the domestic price is higher than the price on the international market, which incentivizes farmers in the country to produce the crop [11].

\subsection{The Probit Model}

The probit model was applied to analyze the household survey data to estimate the factors that determine household's above-average yields. The regressors included socio-economic characteristics of the household such as experience in farming, level of education and size of household; other characteristics include wealth variables such as the number of cattle and total land owned. Furthermore, variables related to field management were included: use of improved seed, the quantity of fertilizer and herbicides applied, labor, and the size of the plots. The probit model is expressed as:

The probit model in its general form is given below:

$$
\mathrm{Y} i=\mathrm{X} i \beta i+\mu i
$$

In this case, the $Y i$ is the dependent variable (farmers producing more than $1.5 \mathrm{Mt} / \mathrm{ha}$ ), $\mathrm{X} i$ is the vector of explanatory variables that contribute to the plot yield above the national average, whereas $\mu i$ is the error term.

The specific probit model used is specified as:

$$
\begin{gathered}
\text { Yi } \beta_{0}+\beta_{1} \text { FarmExp }+\beta_{2} \text { Edu }+\beta_{3} \text { HhSize }+\beta_{4} \text { NCattle }+\beta_{5} \text { FarmSize }+\beta_{6} \text { Ext }+ \\
\beta_{7} \text { ImpSeed }+\beta_{8} \text { Fert }+\beta_{9} \text { Herb }+\beta_{10} \text { Labor }+\beta_{11} \text { PloSize }+\beta_{12} \text { FarmGroup }+\beta_{13} \text { District } 1 \\
+\beta_{14} \text { District } 2+\beta_{15} \text { District } 3+\mu i
\end{gathered}
$$

The socio-economic variables in the empirical model are denoted as follows. FarmExp denotes the experience in farming of the household head and Edu her or his education level. It was hypostasized that with more experience and a higher level of education, farmers would have a better understanding of farm practices and input use. As determinants related to the household's wealth, we included NCattle, which denotes the number of cattle owned, and FarmSize, as it was assumed that better-off farmers are more likely to have better access to resources and therefore achieve higher yields. Ext denotes access to extension services by the household as farmers are more likely to have higher yields as they receive information on practices and input use. ImpSeed refers to the use of seeds other than the ones farmers saved from the previous harvest. Part of the success of the Green Revolution lies in the joint use of seeds, agrochemicals, and fertilizers; therefore, we included this input as regressors. Fert stands for fertilizer and Herb for herbicide. Labor was also included as input variable. As more labor is supplied in a single plot, for example for weeding, the farm will more likely have higher maize yields. PlotSize represents the size of the plot measured by GPS device. Plot size is very much discussed in literature as a factor of productivity and can have either a negative or a positive effect of yield. FarmGroup denotes the participation of the household head in a farm-based organization (FBO). A farmer part of an FBO is expected to have better access to information on market prices, distribution systems and resource use, which can influence the yield performance. Additionally, we controlled for district-specific, non-observed factors (e.g., market access, specific soil, and weather conditions).

\section{Results}

The following section details the results from different analytical methods to assess the comparative advantage in the two production systems and identify the role of inputs and other farm specific factors.

The crop budget is the first important result of the analysis, production revenues and cost of inputs, thus the determination of the farm profits. Table 2 represents the outcome of the crop budget, 
based on the household $(\mathrm{HH})$ questionnaire, illustrating the allocation of household resources and the output in the two systems. Net revenues should be interpreted as returns to land and management skill, since management and land are not charged in the budget. Therefore, net revenue is not "profit" but rather the returns to having land and knowing how to allocate labor and inputs on it. The last row of Table 2 shows household $(\mathrm{HH})$ revenue not accounting family wages. In this case, all systems allocate their resources efficiently. If we consider the opportunity cost of family labor, the outcome highly drops.

Table 2. Crop budget of high and low-output system (values in GHS/ha unless otherwise specified).

\begin{tabular}{|c|c|c|c|}
\hline & & High & Low \\
\hline \multicolumn{2}{|c|}{ Total Grain (Kg/Ha) } & 2149 & 938 \\
\hline \multicolumn{2}{|c|}{ Tradable Inputs } & 152 & 86 \\
\hline \multirow{2}{*}{ Non-Tradable Factors } & HH labor & 142 & 106 \\
\hline & Wage labor & 68 & 30 \\
\hline \multicolumn{2}{|c|}{ Own Capital (Tools and Small Implements) } & 43 & 33 \\
\hline \multicolumn{2}{|c|}{ Service And Non-tradable Inputs } & 116 & 70 \\
\hline \multicolumn{2}{|c|}{ Total Costs } & 521 & 324 \\
\hline \multicolumn{2}{|c|}{ Total Revenue } & 855 & 373 \\
\hline \multicolumn{2}{|c|}{ Net Revenue } & 334 & 49 \\
\hline \multicolumn{2}{|c|}{ Net Revenue (Without HH Labor) } & 476 & 155 \\
\hline
\end{tabular}

Based on crop budget and the secondary data collected from government and research institutions on transport, taxes, levies, subsidies, and other cost we computed the PAM. Tables 3 and 4 present the results for two output systems. Private profits are outcomes of the crop budget and reflect the difference between revenues and costs at current market prices (first row, letter D). Whereas social prices (second row, letter $\mathrm{H}$ ) are used to measures the efficiency and competitive advantage of maize production. The positive outcomes in the high production system indicate efficient use of economic resources, suggesting that production costs are lower than import costs at the current policies and technology adoption. The situation changes in the below average system.

Table 3. Average of PAM values in GHS/ha of 121 farmers in the low-output systems.

\begin{tabular}{ccccc}
\hline Low & Revenues & Input Costs & Factor Cost & Profits \\
\hline Private & $389(\mathrm{~A})$ & $107(\mathrm{~B})$ & $218(\mathrm{C})$ & $64(\mathrm{D})$ \\
Social & $334(\mathrm{E})$ & $107(\mathrm{~F})$ & $217(\mathrm{G})$ & $-10(\mathrm{H})$ \\
Divergences & $55(\mathrm{I})$ & $0(\mathrm{~J})$ & $1(\mathrm{~K})$ & $54(\mathrm{~L})$ \\
\hline
\end{tabular}

Table 4. Average of PAM values in GHS/ha of 54 farmers in the high-output systems.

\begin{tabular}{ccccc}
\hline High & Revenues & Input Costs & Factor Cost & Profits \\
\hline Private & $890(\mathrm{~A})$ & $186(\mathrm{~B})$ & $334(\mathrm{C})$ & $369(\mathrm{D})$ \\
Social & $746(\mathrm{E})$ & $191(\mathrm{~F})$ & $339(\mathrm{G})$ & $234(\mathrm{H})$ \\
Divergences & $144(\mathrm{I})$ & $-5(\mathrm{~J})$ & $-5(\mathrm{~K})$ & $155(\mathrm{~L})$ \\
\hline
\end{tabular}

Private and social prices are import price plus inland transport costs, adjusted for processing losses. The private prices are validated against market prices. In the second row, social outputs (E) are valued at C.I.F. prices since they are treated as exportable, inputs $(\mathrm{F})$ are valued according to F.O.B. prices since they are imported goods, and international prices are used since the products are traded at world prices. 
The divergence, in the third row, between observed private (actual market) and estimated social prices (efficiency) are explained by market failures or policies [13]. Two possible policies influence the divergence observed in input transfers (J) and output transfers (I) between reported and international market prices: either commodity-specific or exchange rate policies. The slight overvaluation of the currency indicates a small divergence in the input transfers $(\mathrm{J})$, although neglectable. All tradable inputs are calculated by separating each component of the intermediate inputs into factor costs and tradable input categories. Output transfers (I) are relatively high compared to input transfers (J). This factor (I) indicates the market price minus the efficiency valuation of maize; the divergence can be attributed to distorting policies, in particular to import and sales tax on goods, since market failures are difficult to identify empirically. Factor transfers $(\mathrm{K})$ are the difference between all factors of production (C) and their social cost $(\mathrm{G})$ : the effects of distorting policies on output or factor markets are very common in developing countries. Net transfers (L) are an important result of the PAM and show the extent of inefficiency of the system; policy can be aimed to reduce the degree of distortion. The positive net transfers (L) suggest that the net effect of policy intervention is increasing production at household level in all systems.

\subsection{Protection and Competitiveness Coefficients}

Protection and competitiveness coefficients of output systems are summarized in Table 5.

Table 5. Protection and competitiveness coefficients derived from PAM.

\begin{tabular}{cccccc}
\hline & EPC & CBR & DRC & NPC $_{\mathbf{O}}$ & NPC $_{\mathbf{I}}$ \\
\hline High & 1.27 & 0.58 & 0.61 & 1.19 & 0.98 \\
Low & 1.24 & 0.84 & 0.96 & 1.16 & 1.00 \\
\hline
\end{tabular}

The Effective Protection Rate (EPC) indicates the effect of protection policies on the agricultural system, combining the effect of commodity price policies. In our case, government's fertilizer subsidies result in a net positive incentive for maize production. Therefore, producers are protected by policy intervention on value added processes. This finding is confirmed by the values of the $\mathrm{NPC}_{\mathrm{O}}$ and $\mathrm{NPC}_{\mathrm{I}}$. Both inputs and outputs are protected by commodity (price) policies. The CBR indicates private profitability. The values of the CBR in the low and high production systems suggest that 0.84 and 0.58 GHS are needed to generate 1 GHS of output in the respective systems. The indicators of comparative advantage are DRC and social profits $(\mathrm{H})$. For both output systems the DRC is less than one, indicating that the systems are economically efficient. However, DRC indicates the cost of domestic factors incurred to obtain one unit of added value in economic terms. The value of 0.61 indicates a higher comparative advantage of maize production of farms in the high-output system, whereas the low-output systems are barely in the range of economic efficiency which is reflected by the negative value (letter F) in Table 3. The NPC ${ }_{O}$ coefficients greater than one, which indicates agricultural policy is protecting the output price at domestic level, raise farm-gate prices to a higher level than the world maize price. The NPC $\mathrm{I}_{\mathrm{I}}$ values close to one indicate that input costs in these systems are only slightly lower and equal (low-output) to the international price.

\subsection{Empirical Probit Model Estimates for High Production Plots}

From the previous section one can conclude that both systems are profiting from the FSP, but the high-output system can make better use of its resources. To identify the factors that contribute to the above-average output of the plots a probit model was computed. The estimates derived are presented in Table 6. The results indicate the regressors, which positively or negatively contributed to the probability of being part of the high-output maize plots, while controlling for variations (e.g., soil and weather) with district dummies. Farmer's experience did significantly affect the yield level, since farmers 
management skills are supposed to increase with experience. The variable on farmer's age was omitted from the model specification since highly correlated with the farming experience variable.

Table 6. Plot specific factors determining the categorization into the high-output systems.

\begin{tabular}{ccc}
\hline & Robust Std. Err. & Marginal Effects \\
\hline Farming experience (years) & 0.003 & $0.006^{*}$ \\
Education HH head (years) & 0.057 & 0.106 \\
Household size & 0.005 & 0.000 \\
No. Cattle & 0.037 & 0.043 \\
Use of improved seeds (dummy) & 0.094 & $0.225^{*}$ \\
Extension service (dummy) & 0.073 & 0.087 \\
Fertilizer (kg/ha) & 0.000 & 0.000 \\
Herbicides (L/ha) & 0.013 & $0.029^{*}$ \\
Labor (person-days/ha) & 0.000 & 0.000 \\
Size of maize plot (ha) & 0.034 & $-0.090^{*}$ \\
Total farm size (ha) & 0.006 & 0.006 \\
Farmers group (dummy) & 0.078 & -0.042 \\
Observations & 175 & \\
Wald Chi2 & $44.53 * * *$ & \\
Log pseudolikelihood & 84.50 & \\
\hline
\end{tabular}

Significant at $10 \%$ level ${ }^{*}$, at $1 \%$ level ${ }^{* * *}$.

Plots with improved seeds had a $22 \%$ higher likelihood to yield above average. In this case, we considered improved seeds as those that were purchased in agro-input dealers' shops in a certified package. The variety that is the most available in the Ghanaian seed market is the open-pollinated variety Obatampa, and a large share of farmers mentioned it as the variety that they purchased. Furthermore, the use of hybrids is very limited in Ghana, about 3\% [14].

The variable addressing the use of herbicides, expressed in liters per hectare, increased the likelihood of a plot to be classified as an above-average output plot. Weeds are a major problem, and if not addressed, fertilizers may support their growths and inhibit maize production. It is also true that weeding is a time-consuming activity and labor is limited during peak seasons. Therefore, herbicide use is a welcoming and efficient alternative to manual labor.

Differently than expected, fertilizer did not have a significant effect and smaller sized plots decreased the likelihood of being part of the high production system. We tested the model against the uncentred variance inflation factor (VIF) test; single regressors all show values below 7 , and an overall mean of 3.43, which indicates no multicollinearity issues.

\section{Discussion}

This study assessed the comparative advantage of maize production in northern Ghana, and the contribution of single inputs, especially fertilizer application, to high-output plots. The results showed that a set of agricultural and macroeconomic policies are supporting competitiveness of maize production as import substitution, this is particularly true for high-output-systems.

The PAM shows that positive private profits are achieved by farmers, indicating cost effectiveness of the production systems in the short to medium term. However, high-output farmers use scarce resources more efficiently. The low-output farmers instead depend more on government intervention at the margin and barely have a comparative advantage in maize production. The negative divergences between private and social costs of domestic factors $(\mathrm{K})$ in the high production systems indicates a reduction of cost to individual farmers, a sign of interventions that lowers the cost of capital and labor. The positive values of the divergences of private and social profits $(\mathrm{L})$ suggest that the net effect of policies on maize production increases profitability in both systems analyzed. The data suggest that, Ghana might not be able to export but is still better off with the domestic production than importing, since C.I.F prices are high compared to F.O.B. prices, respectively 407 and 66 \$ Mt in the survey year 2010. 
The ratios of the protection and competitiveness coefficients are summarized in Table 5. The value of the nominal protection coefficient on tradable outputs, NPCo, is 16 and 19 points higher than one, indicating that the inland farm-gate price is higher than the world trade price due to import duty on maize. The $\mathrm{NPC}_{\mathrm{I}}$ of less than one indicates that the price of tradable inputs is lower than the international market price, suggesting that policies in Ghana are reducing the cost of tradable inputs. This leads to a positive input transfer to the agricultural system, which is confirmed by the government FSP. These two effects, output price and tradable input price, are combined in the EPC. An EPC greater than one indicates how much the observed value differs from what it would be without policy effects, in this case, the value added in private prices and the world prices. The policy transfers from output and input transfers are about $25 \%$ (EPC is 27 and 24 points above 1 in the high and the low system, respectively) greater than private profits would be without policy interventions. The DRC is an indicator of efficiency closely related to the social profits row (E, F, G and H). In the low-output system, the value is closer to one, indicating that the value of domestic resources used in production is higher. This suggests that at the current level of technology and input management, especially in the low-output system, scarce resources are not used efficiently. The policies in place should aim at achieving a comparative advantage for the low-output farm system, since they constitute the larger share of the farms. Production levels below the national average are socially expensive and the import price is lower than the production price. The lower value of DRC of the high-output system indicates a higher comparative advantage.

Overall, the PAM result shows that domestic maize production is barely socially profitable for the low-output farms. With the introduction of the FSP, small landholders had access to initially economically inaccessible inputs. Low-output farmers using fertilizers now depend on government intervention. Furthermore, factor transfers indicate small support of policy intervention in the capital market, which is not very well developed [15], it is expected that lower cost of capital and contribute to private and social profits.

These findings differ from the results of the study by Winter-Nelson and Aggry-Fynn undertaken from November 2007 to February 2008, before the introduction of the FSP. Private input costs in the low-production system are twice as much as in the previous study, e.g., factor costs. The main difference found was that farmers in the previous study did not apply any mineral fertilizer to their maize fields. The higher cost is related to the greater use of fertilizers, a shift that might be related to the governmental FSP introduced in August 2008. With the new policy, smallholder farmers had access to initially economically inaccessible inputs. This massively increased their expenditure. The use of fertilizers presumably also affected labor allocation. Repeated application of fertilizer and the more intense weeding needed due to increased weed growth explain the increased labor costs. Despite increased fertilizer application, maize yield did not improve.

Unlike in the previous study, low-output farmers using fertilizers now depend on government intervention. Factor transfers (K) indicate small support of policy intervention in the capital market (lower cost of capital would increase private and social profits). With values similar to the study of 2008, even with substantially higher private costs, net transfers are positive, and the net effect of policies increased profitability of all systems to the same level as in 2007. Our results also indicate that the income situation did not change due to the fertilizer subsidies program, since farmers spent more to purchase tradable input, but did not obtain higher yields. Leading to the conclusion that the potential of mineral fertilizer is not yet fully realized. The strategy should aim not only to increase the amount of fertilizer used but also invest in extension service to improve management skills that foster production. As the probit model showed other factors contribute more to the probability of a plot to fall in the high-output system than fertilizer. Furthermore, the timing of applications is of primary importance to achieve its full potential of the inputs. It is also known that improved maize varieties adapted to the harsh conditions perform better and would increase fertilizer efficiency. Higher producing systems showcase the importance of using improved maize varieties. Traditionally, farmers save seeds from the previous harvest for the next growing season; in this study only $22 \%$ of the land cultivated with 
maize was sown with purchased seeds. This reduces input costs and problems with an insufficient seed supply. Furthermore, only 7 out of 52 farmers recalled that the extension service officer provided information on seed varieties. The main constraints against adoption of improved seeds mentioned by farmers were lack of financial means $(74 \%)$, the perception that the quality of recycled seeds is enough $(26 \%)$, and lack of knowledge about the existence of improved seeds $(10 \%)$. The results are reflected in a recent study, in the same region, which reports that only $3 \%$ of the farmers grow hybrids [16]. The MoFA district office was reported to be one of the few places where seeds could be purchased, aside from the input dealers but, both rarely had them available. The same problem was observed for fertilizers, which hinders appropriate application. Poor input availability is a major reason for low productivity [17]. Furthermore, farmers prefer the well-known, open-pollinated varieties (OPVs), especially Obatampa which was released in 1992 and is since than the most popular variety [18]. With proper management this variety has the potential to yield up to $4.6 \mathrm{Mt} / \mathrm{ha}$ as shown in both on-station and on-farm trials [18]. However, varieties such as Sanzal-sima, known as one tolerant to drought and parasitic weed Striga sp., and Mamaba, a hybrid maize variety, were not known by the households even though they have very good yield performances in northern Ghana [19]. Besides the price ( $50 \%$ more than for Obatampa), hybrids are considered risky since its characteristics are lost when replanted and they are in greater need for inputs. Farmers investing in improved seeds may increase their yield to $2.3 \mathrm{Mt} / \mathrm{ha}$ and those combining them with fertilizers achieve up to $3.4 \mathrm{Mt} / \mathrm{ha}$ also in dry areas; however initial costs and risks are higher [20]. The findings from the probit model fall in line with the literature, as the use of improved seeds was significant in high-output farms. Only 26 farmers used to buy seeds of which 21 fall in the high producing category. However, the use of fertilizer was not significant to explain the likelihood of being part of the high-yield plots. This is surprising and questions the importance of the FSP. Farmer's experience, the use of herbicides and improved seeds were significant, which illustrates that better farm management and complementing inputs need as much attention as fertilizers alone. In Ghana, the extension service coverage is very low (1 officer for about 1000 farmers) and the information material available is very limited [21]. This explains why the extension service variable in the probit did not have a significant effect on agricultural productivity. The low outreach of the service is very limited, only $26 \%$ of the interviewed households had received extension service in the previous two years. This reflects the literature on Ghana which shows that only $12 \%$ of farmers had adopted a new technique in the previous two years, indicating that farmers face considerable challenges to innovate [22]. Low access to physical resources for transport and trainings, low salary, as well as lack of training and incentives are affecting the quality of the extension officer's service delivery. Extension service and the education system are key policy instruments to improve productivity in agriculture [23].

Farmers mentioned only two types of fertilizer SoA (Sulphate of Ammonia) and NPK (Nitrogen, Phosphorus and Potassium), yet little was known about their composition, efficient application methods, and timing. Correct timing of mineral fertilizer application is important to ensure maximum efficiency and reduce runoff and leaching. Cost-efficient measures to improve soil fertility can also be achieved through soil conservation practices, such as mulching to increase soil organic matter, reduce kinetic energy of runoff and increase soil moisture. Fertilizer use must be supported by training to avoid wastage and negative externalities. Major constraints in crop production perceived by the farmers interviewed include other aspects, such access to financial services, access to extension services and pest control. The lack of information on improved seeds, insecticides, and pesticides, as well as lack of a well-developed seed supply system clearly affects adoption rate $[24,25]$. Though some farmers claimed that they do not need seeds or that improved seeds are not profitable, price is an important factor preventing adoption [26], as fertilizer price is.

The FSP targets only one variable, but the results confirm that other factors are equally important to improve biomass production and food security in the study region. The adoption of improved maize varieties, proper timing of fertilizer application, good agricultural practices to improve soil fertility and a functioning extension service that provides information on management practices are pivotal to 
the close the yield gap in northern Ghana. The World Bank underlines the need to offer major inputs (fertilizers, agrochemicals, and improved seed) as a package and to improve the currently fragmented distribution network [27]. The use of complementary inputs and management practices that consider soil parameters and include local limitations are likely have the potential to increase yields more than if the focus is only on fertilizers [28,29]. It is also true that farmers face resource constrains (e.g., financial and labor) to follow the recommendations of fertilizer application (e.g., timing advices and application modalities) [30].

Political forces and priorities play a part in the allocation of government's resources. An empirical study examined the effect of districts' political characteristics on fertilizer voucher allocation in 2008. The program first targeted districts where the ruling party had lost support in the previous elections and more intensively those districts that registered high percentage losses. This type of allocation was not efficiency-based but politically orientated, resulting in fewer vouchers to poorer farmers. According to this study, the three regions where we conducted our survey rank in the top four positions for average number of vouchers available per 1000 farmers [7]. Governance challenges of the FSP are found to still affect targeting of smallholder farmers in Ghana [9].

\section{Conclusions}

This research uses the PAM approach to analyze the comparative advantage of two systems of maize production in the northern Ghana. The agricultural sector is important to Ghana's economy, and as stated by many authors, agricultural growth in early stages of development has the greatest impact on overall economic performance and poverty reduction.

The data show that even the northern regions of Ghana, where the environmental conditions are harsh the high-output system has the comparative advantage in maize production. The lack of access to information on crop management and improved technologies prevents small-scale farmers from realizing their crops full potential. This is coupled with a weak financial and credit system and poor infrastructure. However, the use of fertilizer, under the current conditions, did not increase the likelihood of producing more than the national average, whereas other measures have a higher impact on maize yield and should be considered by policy makers to bridge the productivity gap. This is an important finding, especially looking at the controversial policy issue debated in many African countries.

In conclusion, maize production systems have the potential to increase productivity to ensure food security and meet the challenges of biomass use in the bioeconomy. However, the policy measures need to address more than just the increased use of fertilizer. The combined access to information and new technologies, as well as the improvement of soft and hard infrastructure to reach out to a larger number of rural communities, are considered to be pivotal for the development of the agricultural sector, especially in the northern Ghana.

Author Contributions: L.S. and R.B. conceptualization, design and analysis; L.S. investigation and writing.

Funding: The research conducted for this paper was supported by the International Food Policy Research Institute (IFPRI) and by the German Federal Ministry of Education and Research (BMBF). The BMBF funds are part of the collaborative project "Improving food security in Africa through increased system productivity of biomass-based value webs" (BiomassWeb); the project is part of the GlobE-Research for the Global Food Supply programme (Grant No. 031A258H).

Acknowledgments: The authors are thankful to Alex Winter-Nelson, University of Illinois, USA, Shashi Kolavalli from IFPRI, Ghana, and to Felix Asante from the University of Ghana, Legon, for their input during conceptualization and design of the study, and their support during field research. We would like to express our gratitude to Yaa Adwinmea Attipoe and Harald Zeller for their assistance during data collection. We would also like to convey our heartfelt appreciation to the communities and respondents from the local institutions who kindly contributed their valuable time towards the data collection. Our sincerest thanks go to the reviewers for their comments and suggestion on the earlier version of this paper.

Conflicts of Interest: The authors declare no conflict of interest. 


\section{References}

1. Virchow, D.; Beuchelt, T.D.; Kuhn, A.; Denich, M. Biomass-Based Value Webs: A Novel Perspective for Emerging Bioeconomies in Sub-Saharan Africa. In Technological and Institutional Innovation for Marginalized Smallholders in Agricultural Development; Gatzweiler, F.W., von Braun, J., Eds.; Springer International Publishing: Basel, Switzerland, 2016; pp. 225-238.

2. Ministry of Food and Agriculture (MoFA). Agriculture in Ghana: Facts and Figures 2015. Statistics, Research and Information Directorate; MoFA: Accra, Ghana, 2016.

3. Quiñones, E.J.; Diao, X. Assessing Crop Production and Input Use Patterns in Ghana-What Can We Learn from the Ghana Living Standards Survey (GLSS5); Ghana Strategy Support Program (GSSP) Working Paper No. 0024; International Food Policy Research Institute: Accra, Ghana, 2011.

4. FAOSTAT. Available online: http://www.fao.org/faostat/en/\#home (accessed on 14 September 2018).

5. FAO. Ghana Country Fact Sheet on Food and Agriculture Policy Trend; APDA-Food and Agriculture Policy Decision Analysis: Rome, Italy, 2015.

6. Benin, S.; Johnson, M.; Abokyi, E.; Ahorbo, G.; Jimah, K.; Nasser, G.; Owusu, V.; Taabazuing, J.; Albert, T. Revisiting Agricultural Input and Farm Support Subsidies in Africa: The Case of Ghana's Mechanization, Fertilizer, Block Farms, and Marketing Programs; IFPRI Discussion Paper 01300; International Food Policy Research Institute: Accra, Ghana, 2013.

7. Banful, A.B. Old Problems in the New Solutions? Politically Motivated Allocation of Program Benefits and the 'New' Fertilizer Subsidies. World Dev. 2011, 39, 1166-1176. [CrossRef]

8. Houssou, N.; Andam, K.S.; Collins, A.-A. Can Better Targeting Improve the Effectiveness of Ghana's Fertilizer Subsidy Program? Lessons from Ghana and Other Countries in Africa South of the Sahara; IFPRI Discussion Paper 1605; International Food Policy Research Institute: Accra, Ghana, 2017.

9. Resnick, D.; Mather, D. Agricultural Inputs Policy under Macroeconomic Uncertainty: Applying the Kaleidoscope Model to Ghana's Fertilizer Subsidy Programme (2008-2015); Discussion Paper 01551; International Food Policy Research Institute: Accra, Ghana, 2016.

10. Winter-Nelson, A.; Aggrey-Fynn, E. Identifying Opportunities in Ghana's Agriculture: Results from a Policy Analysis Matrix; Ghana Strategy Support Program (GSSP) Background Paper No. 12; International Food Policy Research Institute: Accra, Ghana, 2008.

11. Monke, E.; Pearson, S. The Policy Analysis Matrix for Agricultural Development; Cornell University: Ithaca, NY, USA, 1989; ISBN 0-8014-9551-2.

12. Shapiro, I.B.; Staal, J.A. The Policy Analysis Matrix Applied to Agricultural Commodity Markets. In Price, Products and Market: Analyzing Agricultural Markets in Developing Countries; Lynne Rienner Pub. Inc.: Boulder, CO, USA, 1995; pp. 73-96.

13. Ogbe, O.A.; Okoruwa, V.O.; Jelili, S.O. Competitiveness of Nigerian Rice and Maize Production Ecologies: A Policy Analysis Approach. Trop. Subtrop. Agroecosyst. 2011, 14, 493-500.

14. Tripp, R.; Ragasa, C. Hybrid Maize Seed Supply in Ghana; Ghana Strategy Support Program (GSSP) Working Paper No. 40; International Food Policy Research Institute: Accra, Ghana, 2015.

15. Nair, A.; Fissha, A. Rural Banking: The Case of Rural and Community Banks in Ghana; Agriculture and Rural Development Discussion Paper 48; World Bank: Washington, DC, USA, 2010.

16. Morris, M.L.; Tripp, R.; Dankyi, A. Adoption and Impacts of Improved Maize Production Technology: A Case Study of the Ghana Grains Development Project; Economics Program Paper 99-01; CIMMYT: Mexico City, Mexico, 1999.

17. Feder, G.; Richard, E.J.; Zilberman, D. Adoption of Agricultural Innovations in Developing Countries: A Survey. Econ. Dev. Cult. Chang. 1985, 33, 255-298. [CrossRef]

18. Ragasa, C.; Dankyi, A.; Acheampong, P.; Wiredu, A.N.; Chapoto, A.; Asamoah, M.; Tripp, R. Patterns of Adoption of Improved Rice Technologies in Ghana; Ghana Strategy Support Program (GSSP) Working Paper, No. 36; International Food Policy Research Institute: Accra, Ghana, 2013. [CrossRef]

19. Wiredu, A.N.; Gyasi, K.O.; Abdoulaye, T.; Sanogo, D.; Langyintuo, A. Characterization of Maize Producing Households in the Northern Region of Ghana Country Report-Household Surve Y Characterization of Maize Producing Households in the Northern Region of Ghana; CSIR-SARI: Tamale, NY, USA, 2008. 
20. WABS Consulting Ltd. Draft Report: Maize Value Chain Study in Ghana: Enhancing Efficiency and Competitiveness. Available online: http://www.valuechains4poor.org/file/Maize_Value\%20Chain_WAB_ Dec_08.pdf (accessed on 16 August 2018).

21. Sam, J.; Osei, S.K.; Dzandu, L.P. Evaluation of Information Needs of Agricultural Extension Agents in Ghana. Inf. Dev. 2017, 33, 463-478. [CrossRef]

22. Belden, C.; Birner, R.; Asante, F.; Horowitz, L. Agricultural Extension in Ghana Results of a Survey of Agricultural Extension Agents in Six Districts. 2010. Available online: https:/ / gssp.files.wordpress.com/ 2010/05/agricultural_extension_draft.pdf (accessed on 16 August 2018).

23. Binam, N.J.; Tonye, J.; Nyambi, G.; Akoa, M. Factors Affecting the Technical Efficiency among Smallholder Farmers in the Slash and Burn Agriculture Zone of Cameroon. Food Policy 2008, 29, 531-545. [CrossRef]

24. Doss, C.R.; Morris, M.L. How Does Gender Affect the Adoption of Agricultural Innovations? The Case of Improved Maize Technology in Ghana. Agric. Econ. 2001, 25, 27-39. [CrossRef]

25. Poku, A.-G.; Birner, R.; Gupta, S. Why Do Maize Farmers in Ghana Have a Limited Choice of Improved Seed Varieties? An Assessment of the Governance Challenges in Seed Supply. Food Secur. 2018, 10, $27-46$. [CrossRef]

26. Tahirou, A.; Sanogo, D.; Langyintuo, A.; Bamire, S.A.; Olanrewaju, A. Assessing the Constraints Affecting Production and Deployment of Maize Seed in DTMA Countries of West Africa; IITA: Ibadan, Nigeria, 2009; ISBN 978-131-342-0.

27. World Bank. Awakening Africa's Sleeping Giant: Prospects for Commercial Agriculture in the Guinea Savannah Zone and Beyond; World Bank: Washington, DC, USA, 2009; ISBN 978-0-8213-7941-7.

28. Marenya, P.P.; Barrett, C.B. State-Conditional Fertilizer Yield Response on Western Kenyan Farms. Agric. Appl. Econ. Assoc. 2009, 91, 991-1006. [CrossRef]

29. Scheiterle, L.; Häring, V.; Birner, R.; Bosch, C. Soil, striga or subsidies? Determinants of maize productivity in northern Ghana. Agric. Econ.. Unpublished work.

30. Van Asselt, J.; Di Battista, F.; Kolavalli, S.; Udry, C. Agronomic Performance of Open Pollinated and Hybrid Maize Varieties Results from on-Farm Trials in Northern Ghana; Ghana Strategy Support Program (GSSP) Working Paper 44; International Food Policy Research Institute: Accra, Ghana, 2018. 